\title{
Thoracolumbar vertebral fractures in Sweden: an analysis of 13,496 patients admitted to hospital
}

\author{
Karl-Åke Jansson • Paul Blomqvist • Per Svedmark • \\ Fredrik Granath · Erik Buskens • Martin Larsson • \\ Johanna Adami
}

Received: 3 March 2010/Accepted: 22 April 2010/Published online: 7 May 2010

(C) The Author(s) 2010. This article is published with open access at Springerlink.com

\begin{abstract}
National Longitudinal data of thoracolumbar fracture incidence, trends or mortality rates are lacking. The correlation between admissions and operations of thoracolumbar vertebral fractures has not been investigated. The aim of our nationwide population-based epidemiological study was to analyse the incidence, admissions, operations, and case fatality rate among patients with thoracolumbar vertebral fractures admitted to hospital in Sweden. The Swedish Hospital Discharge Register (SHDR) and the Cause of Death Register (CDR) were linked to determine the incidence of surgical interventions, trends, characteristics of the patients, and case fatality rate for thoracolumbar vertebral fractures based on comprehensive national data. The annual incidence of thoracolumbar fractures was on average 30 per 100,000 inhabitants and did not change considerably during the study period. Among patients younger than 60 years of age the annual incidence was 13 per 100,000 and was twice as high in men compared to women. The proportion operated on was $15 \%$. In the age-group 60 years and
\end{abstract}

K.-Å. Jansson $(\bowtie) \cdot$ P. Svedmark

Section of Orthopaedics, Department of Molecular Medicine and Surgery, Karolinska Institutet at Karolinska University Hospital, Solna, Stockholm, Sweden

e-mail: karl-ake.jansson@karolinska.se; karl-ake.jansson@ki.se

P. Blomqvist · F. Granath · J. Adami

Clinical Epidemiology Unit, Department of Medicine Solna,

Karolinska Institutet, 17176 Stockholm, Sweden

E. Buskens

Department of Epidemiology, University Medical Center Groningen, University of Groningen, 9700 RB Groningen, the Netherlands

M. Larsson

Department of Medicine, Stockholm South General Hospital

at Karolinska Institutet, 11883 Stockholm, Sweden older the majority were women. In this group two percent were operated on. However, males were operated on twice as often as women. The 90-day case-fatality rate after surgery was $1.4 \%$. This information may assist health care providers in health care planning. Moreover, these data can also be used for power calculations when planning future clinical studies.

Keywords Case fatality rate - Epidemiology · Mechanism of injury - Population based study . Spine $\cdot$ Vertebral fractures
Abbreviations
CDR Cause of Death Register
ICD International Classification of Diseases
PIN Personal identity number
SHDR Swedish Hospital Discharge Register

\section{Introduction}

There are few international studies with population based data on the epidemiology of vertebral fractures. Most earlier epidemiological studies were retrospective case series or from single hospitals $[1,2]$. In previous studies, the annual fracture incidence varied from 23 to 90 per 100,000 inhabitants [1, 3-9]. The Framingham cohort study included 5,209 patients with a mean age of 44 years (range 28-62 years) and a prevalence of vertebral fracture of $14 \%$ [8].

In Sweden, with a population of 9.2 million, about 2,700 patients with thoracolumbar vertebral fractures are admitted to hospitals annually. Most of these fractures are caused by blunt trauma $[6,7]$. In younger patients, thoracolumbar 
vertebral fractures are usually caused by high energy accidents such as falls, or motor vehicle accidents whereas in elderly patients, osteoporosis is the dominant etiology [10]. Many patients have permanent functional impairment and pain. Long term reductions in quality of life and ability to work are frequent $[10,11]$.

Treatment of thoracolumbar vertebral fractures has been debated extensively [12-23]. Three comprehensive reviews of unstable traumatic thoracolumbar vertebral fracture management did not find any clear pattern in the relative merits of operative compared to non-operative treatment $[13,21,22]$.

To our knowledge, previous studies have not investigated the proportion of patients admitted for thoracolumbar vertebral fractures and operated on. Therefore, the aim of our nationwide population-based epidemiological study was to analyse the incidence, admissions, operations, external causes, and case fatality rate among patients with thoracolumbar vertebral fractures admitted to hospital in Sweden.

\section{Patients and methods}

Sweden has a national public healthcare system, based on independent county councils, mainly financed by local taxes.

Since 1964, the Swedish National Board of Health and Welfare has compiled data on hospital discharges in the Swedish Hospital Discharge Register (SHDR) [24]. From 1997 onward all Swedish hospitals participate. Each record contains information about demographics, diagnoses, operations, and administrative data about the healthcare provider and the admission. Each year, about 1.3 million discharges are recorded. The validity of the data in the Register has previously shown to be adequate [25].

We identified all patients with a primary discharge diagnosis of thoracic or lumbar vertebral fractures, spine dislocations, or disc ruptures in the SHDR (ICD 10 S22.0, S22.1, S23.0, S23.1, S32.0, S32.1, S33.0, S33.1, International Classification of Diseases, 1997) [26]. Surgery in these patients was categorized by procedure codes indicating spine operations (NA***), and operations on the nervous system (A****; Nordic Classification of Operations and Major Procedures, 1997) [27]. The standard diagnostic workup was examination of clinical signs and radiological examination.

In order to assess survival, linkage was performed to the Swedish Death Register using the unique personal identity number (PIN) [28]. From this register, information was obtained about underlying cause of death, and date of death. All patients were followed from January 1, 1997 through December 31, 2001 or date of death. Both these registers are maintained by the Centre of Epidemiology,
National Board of Health and Welfare, Stockholm Sweden. (WWW.sos.se/epc/epceng.htm).

Age was categorized as 0-19, 20-29 years etc. and 80 -years. In the descriptive and multivariate analyses, patients were stratified by age $0-59$ years or 60 years and older.

Causes of fractures were reported for $95 \%$ of the patients and were grouped into six categories by ICD E-codes (External causes).

All patients operated on during their first admission and, in addition, patients having a first admission without surgery but a second or a later admission with an operation were identified. No readmissions were counted. Indication for surgery was based on the clinicians' evaluations.

Cases fatality rates at 30 and 90 days were calculated at time at risk from the date of admission to the date of death.

The study was approved by the Regional Research Ethics Board (Dnr 04-530/5).

\section{Statistical analyses}

Incidence rates of thoracolumbar vertebral fractures and surgical procedures were calculated from the Swedish national and regional population in the year 2000 (Statistics Sweden) [24]. Only patients with complete records were included. Multivariate logistic regression analyses were performed to estimate the probability of surgery considering sex, age, primary diagnosis, external cause of fracture, year of operation, and geographic region. Odds ratios (OR) and the corresponding 95\% confidence intervals were calculated.

\section{Results}

The study base consisted of 13,496 admitted patients. Of these, a third (34\%) was aged 0-59 years (Table 1a) and a majority was men (62\%). The most frequent external causes were transport accidents and falls from heights.

Among the 4,530 patients aged 0-59 years, 684 patients $(15 \%)$ were operated on. Surgery was most frequent in the patients 20-39 years of age. The crude annual proportion operated on decreased over the study years.

The 8,966 patients 60 years or older (Table $1 \mathrm{~b}$ ) constituted two-thirds of the study population (66\%), and twothirds were women $(68 \%)$. More than half of the patients were 80 years or older, the majority with lumbar vertebral fractures, most of them caused by falls at the same level. The crude annual number of patients admitted decreased slightly over the study years.

Operations were uncommon in these older patients $(2 \%)$. It was four times more frequent in men than in women (4 vs. $1.0 \%$ ) and most operations were performed 
Table 1 Thoracolumbar fractures in Sweden 1997-2001

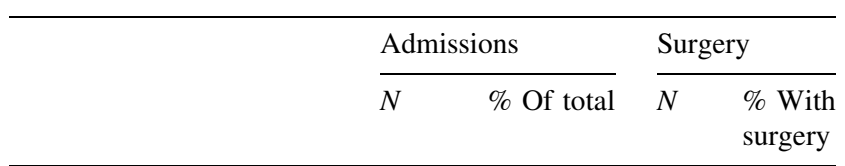

A. Patients $0-59$ years $n=4,530$

Sex

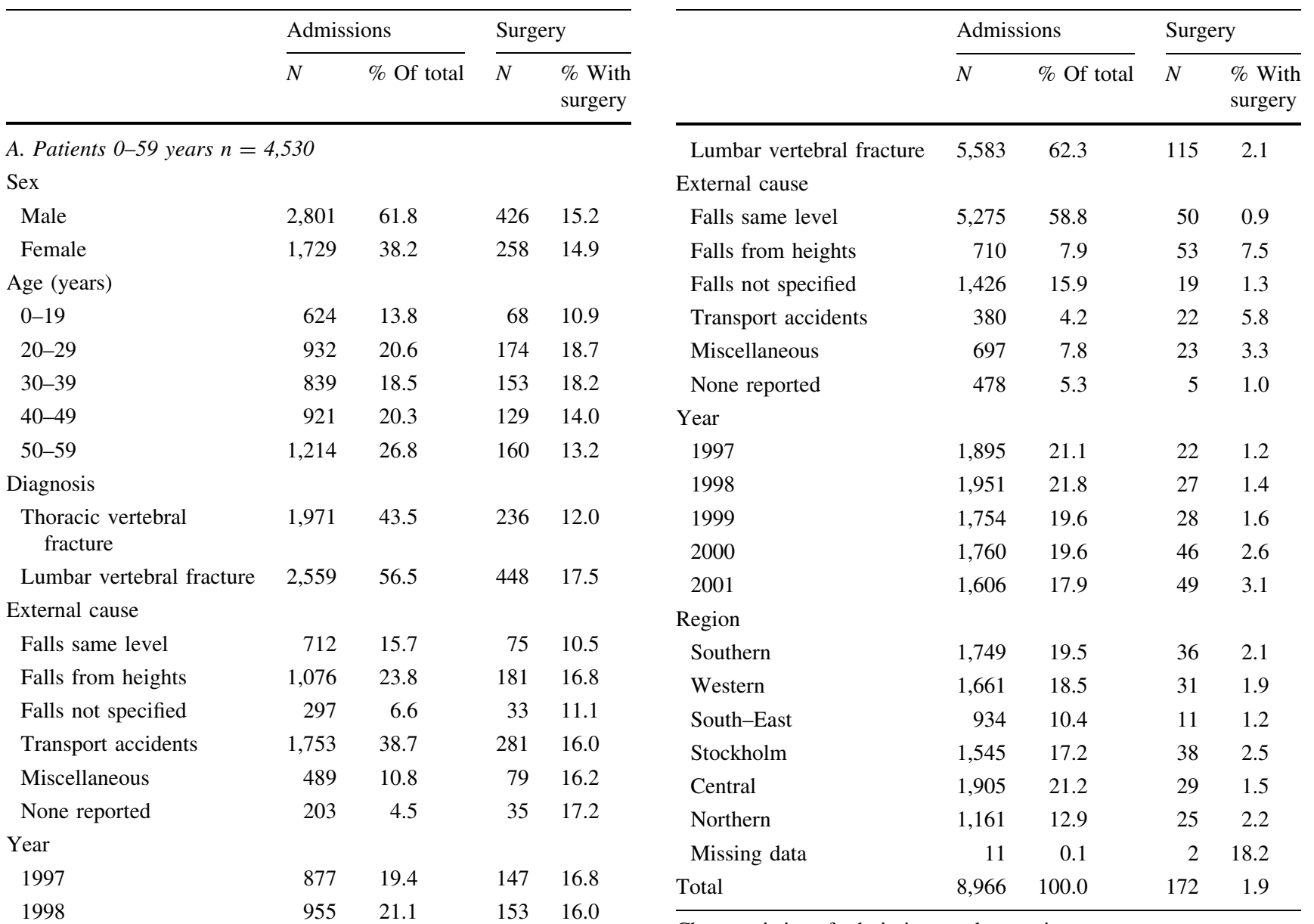

$\begin{array}{lllll}1999 & 902 & 19.9 & 124 & 13.7\end{array}$

$\begin{array}{lllll}2000 & 873 & 19.3 & 138 & 15.8\end{array}$

$\begin{array}{lllll}2001 & 923 & 20.4 & 122 & 13.2\end{array}$

Region

Southern

$\begin{array}{llll}805 & 17.8 & 137 & 17.0\end{array}$

Western

$775 \quad 17.1$

$137-17.0$

South-East

502

17.1

$93 \quad 12.0$

Stockholm

798

11.1

$75 \quad 14.9$

Central

949

17.6

$149 \quad 18.7$

$133 \quad 14.0$

Northern

Missing data

$686 \quad 15.1$

$96 \quad 14.0$

$1 \quad 6.7$

$684 \quad 15.1$

Total

$4,530 \quad 100.0$

B. Patients 60-years $n=8,966$

Sex

\begin{tabular}{lrlrr} 
Male & 2,891 & 32.2 & 113 & 3.9 \\
Female & 6,075 & 67.8 & 59 & 1.0 \\
Age (years) & & & & \\
$60-69$ & 1,311 & 14.6 & 91 & 6.9 \\
$70-79$ & 3,051 & 34 & 59 & 1.9 \\
$\quad 80-$ & 4,604 & 51.3 & 22 & 0.5 \\
$\begin{array}{l}\text { Diagnosis } \\
\text { Thoracic vertebral } \\
\quad \text { fracture }\end{array}$ & 3,383 & 37.7 & 57 & 1.7 \\
\hline
\end{tabular}

Table 1 continued

Characteristics of admissions and operations

in patients 60-69 years of age. The crude annual proportion of patients operated on increased each year.

To accommodate the impact of each variable on the probability of spine surgery, a multivariate analysis was performed for the two age groups (Table 2). In patients 0-59 years of age at surgery, we found no difference between sexes but the probability was significantly higher in the youngest patients from 21 to 39 years of age. Patients with thoracic fractures had a lower probability than those with lumbar fractures. Patients who had fallen from heights or were injured by transport accidents had an increased probability. The probability of surgery was lowest in the western region. There were no changes over time.

In patients 60 years or older, men had a significantly higher probability of an operation than women, and the probability decreased steeply with increasing age. The highest probability was seen in patients who had fallen from heights or suffered from transport accidents. The probability increased significantly during the last 2 years. There were no significant differences between geographical regions. 
Table 2 Thoracolumbar vertebral fractures in Sweden 1997-2001

\begin{tabular}{|c|c|c|c|c|}
\hline & \multicolumn{2}{|c|}{$0-59$ years } & \multicolumn{2}{|c|}{60 -years } \\
\hline & OR & $95 \% \mathrm{CI}$ & OR & $95 \% \mathrm{CI}$ \\
\hline \multicolumn{5}{|l|}{ Sex } \\
\hline Female & 1.00 & Ref. & 1.00 & Ref. \\
\hline Male & 0.98 & $(0.82-1.16)$ & 2.42 & $(1.70-3.45)$ \\
\hline \multicolumn{5}{|l|}{ Age (years) } \\
\hline$\leq 20$ & 1.00 & Ref. & & \\
\hline $21-29$ & 1.83 & $(1.34-2.50)$ & & \\
\hline $30-39$ & 1.77 & $(1.28-2.43)$ & & \\
\hline $40-49$ & 1.31 & $(0.94-1.81)$ & & \\
\hline $50-59$ & 1.24 & $(0.90-1.69)$ & & \\
\hline $60-69$ & & & 1.00 & Ref. \\
\hline $70-79$ & & & 0.42 & $(0.30-0.61)$ \\
\hline $80-89$ & & & 0.14 & $(0.08-0.23)$ \\
\hline \multicolumn{5}{|l|}{ Diagnosis } \\
\hline Lumbar vertebral fracture & 1.00 & Ref & 1.00 & Ref \\
\hline Thoracic vertebral fracture & 0.65 & $(0.55-0.77)$ & 0.73 & $(0.52-1.03)$ \\
\hline \multicolumn{5}{|l|}{ External cause } \\
\hline Falls same level & 1.00 & Ref. & 1.00 & Ref. \\
\hline Falls from heights & 1.59 & $(1.19-2.14)$ & 3.32 & $(2.13-5.19)$ \\
\hline Falls not specified & 0.96 & $(0.62-1.50)$ & 1.36 & $(0.79-2.37)$ \\
\hline Transport accidents & 1.44 & $(1.09-1.90)$ & 2.92 & $(1.67-5.12)$ \\
\hline Miscellaneous & 1.52 & $(1.07-2.15)$ & 2.71 & $(1.59-4.60)$ \\
\hline None reported & 1.73 & $(1.10-2.71)$ & 1.11 & $(0.43-2.88)$ \\
\hline \multicolumn{5}{|l|}{ Year } \\
\hline 1997 & 1.00 & Ref. & 1.00 & Ref. \\
\hline 1998 & 0.99 & $(0.76-1.28)$ & 1.07 & $(0.59-1.93)$ \\
\hline 1999 & 0.83 & $(0.63-1.09)$ & 1.37 & $(0.77-2.44)$ \\
\hline 2000 & 1.02 & $(0.78-1.32)$ & 2.19 & $(1.29-3.71)$ \\
\hline 2001 & 1.03 & $(0.79-1.35)$ & 2.93 & $(1.73-4.97)$ \\
\hline \multicolumn{5}{|l|}{ Region } \\
\hline Southern & 1.00 & Ref & 1.00 & Ref \\
\hline Western & 0.61 & $(0.45-0.82)$ & 0.93 & $(0.56-1.55)$ \\
\hline South-East & 0.75 & $(0.54-1.03)$ & 0.54 & $(0.26-1.09)$ \\
\hline Stockholm & 1.05 & $(0.81-1.37)$ & 1.21 & $(0.74-1.96)$ \\
\hline Central & 0.74 & $(0.56-0.97)$ & 0.60 & $(0.35-1.00)$ \\
\hline Northern & 0.73 & $(0.55-0.98)$ & 0.73 & $(0.42-1.27)$ \\
\hline
\end{tabular}

Probability of spine surgery Odds ratios (OR) and 95\% confidence intervals $(95 \% \mathrm{CI})$

The operations were mainly performed at university or regional hospitals (83\% of the admissions), and most patient were discharged from departments of orthopaedic surgery $(85 \%)$. The median length of stay was 8 days, changing only slightly during the study period.

Among those who were operated the 30 day case fatality rate was $0.7 \%$ and the 90 -day case fatality rate was $1.4 \%$. Median age for those who died was 64 years (Range 4483 years). Common underlying causes of deaths were

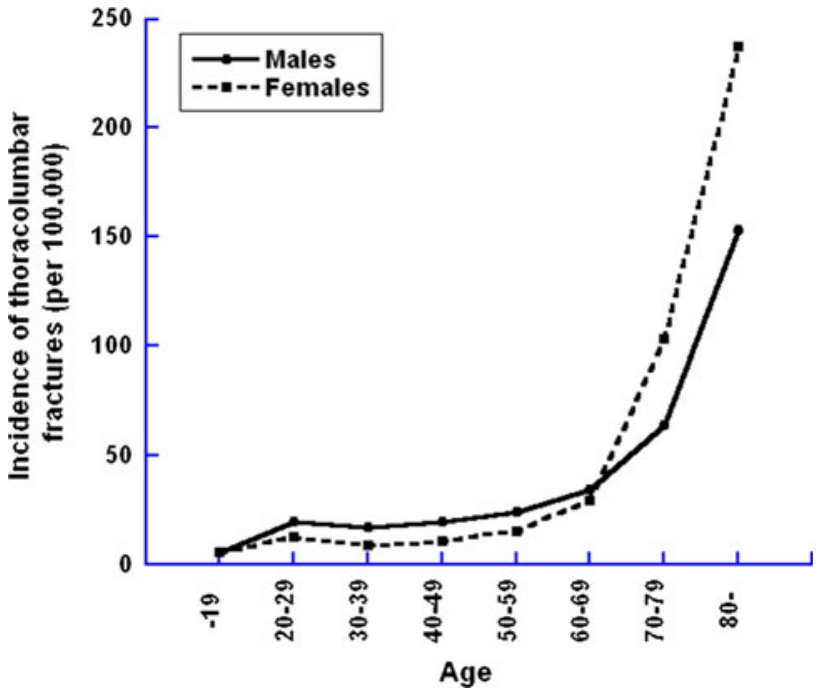

Fig. 1 Thoracolumbar vertebral fractures in Sweden 1997-2001. Age and sex specific incidence per 100,000 population

Table 3 Thoracolumbar vertebral spine fractures in Sweden 19972001

\begin{tabular}{|c|c|c|c|c|c|c|}
\hline \multirow[t]{2}{*}{ Age } & \multicolumn{3}{|c|}{ Fractures } & \multicolumn{3}{|c|}{ Operations } \\
\hline & $0-59$ & $60-$ & All & $0-59$ & $60-$ & All \\
\hline \multicolumn{7}{|l|}{ Year } \\
\hline 1997 & 12.7 & 97.2 & 31.3 & 2.1 & 1.1 & 1.9 \\
\hline 1998 & 13.8 & 99.7 & 32.8 & 2.2 & 1.4 & 2.0 \\
\hline 1999 & 13.1 & 89.3 & 30.0 & 1.8 & 1.4 & 1.7 \\
\hline 2000 & 12.6 & 89.0 & 29.6 & 2.0 & 2.3 & 2.1 \\
\hline 2001 & 13.2 & 80.5 & 28.2 & 1.7 & 2.4 & 1.9 \\
\hline \multicolumn{7}{|l|}{ Region } \\
\hline Southern & 12.1 & 88.2 & 29.6 & 2.1 & 1.8 & 2.0 \\
\hline Western & 13.3 & 101.2 & 32.7 & 1.6 & 1.9 & 1.7 \\
\hline South-East & 13.4 & 81.6 & 29.4 & 2.0 & 1.0 & 1.8 \\
\hline Stockholm & 10.6 & 88.1 & 25.2 & 2.0 & 2.2 & 2.0 \\
\hline Central & 12.9 & 85.0 & 29.7 & 1.8 & 1.3 & 1.7 \\
\hline Northern & 20.1 & 108.9 & 41.3 & 2.8 & 2.3 & 2.7 \\
\hline
\end{tabular}

Annual incidence of fractures and operations per 100,000 population

suicides, intoxications and accidents (29\%), cardiovascular diseases (27\%), and tumours (12\%).

The average annual incidence of patients admitted to hospital with thoracolumbar vertebral fractures was 30.4 per 100, 000 person year (Fig. 1). In patients younger than 60 years of age, the incidence was 13 and twice as high in men as in women. The incidence increased steeply with age and in patients 60 years or older, it was higher in women than in men.

The annual incidence decreased slightly from 1997 to 2001 (Table 3). In patients 59 years or younger, the incidence was stable but decreased by $21 \%$ in older patients. The incidence was higher in the South-Eastern and 


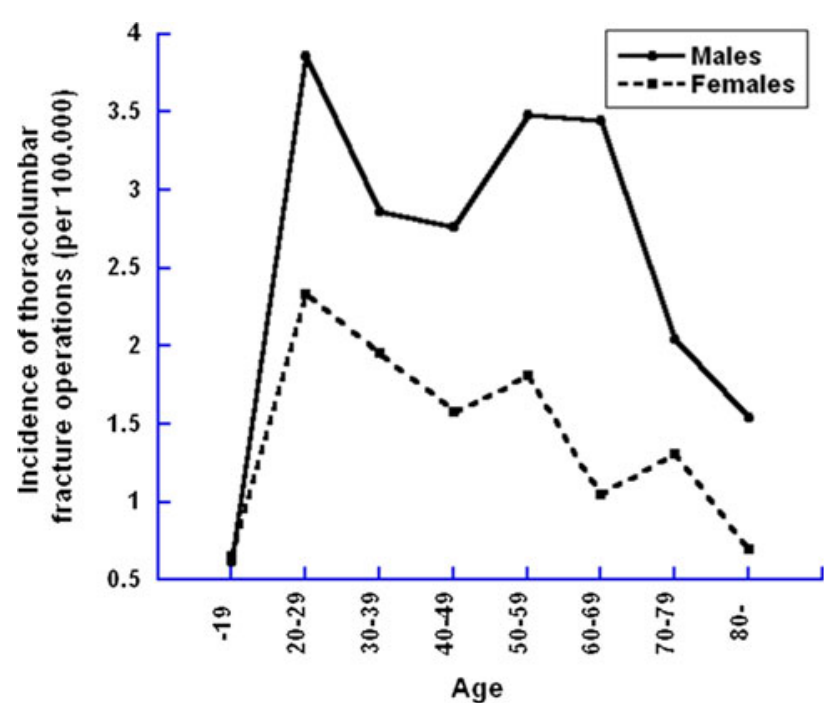

Fig. 2 Thoracolumbar vertebral fractures in Sweden 1997-2001. Age and sex specific surgical incidence per 100,000 population

Northern regions. The annual incidence of operations was 2 per 100,000 person and year with small changes over the study years. The incidence of operations was highest in the Northern region, was twice as high in men as in women, and decreased with increasing age (Fig. 2).

\section{Discussion}

In our study the incidence of thoracolumbar fractures was 13 per 100,000 inhabitants per year in patients younger than 60 years of age, and twice as common in men as in women.

Transport accidents and falls from heights were frequent causes. One patient in seven was operated on, and the probability was unchanged over the study period. Patients older than 60 years of age were mainly women, and only two percent were operated on. Males were operated on twice as often as women and the most common accidents were falls on a level. The probability of an operation increased the last two study years. The case fatality rate was very low.

In contrast to our study a Finnish study conducted 1970-1995 predicted the overall fall-induced fracture incidence in the population older than 50 years to be 32 per 100,000 in 2010 [7]. The study design was different comparing patients aged 50 years or older to a reference group of patients aged 20-39 years. The time period differed, 1970-1995, from which they made further prognosis. Another study performed in an earlier time period with long term follow-up, also reports higher incidences [8]. The low incidence figures in our study could be due to the fact that the total incidence of vertebral fractures remains largely underestimated. A population based study showed that only about one-third of vertebral fractures comes to medical attention, whereas the majority remains unnoticed [5]. However, our study design was unable to detect these asymptomatic osteoporotic fractures. Only large population-based cohort studies which screen all participants would be able to elucidate this aspect. Up to $35 \%$ of unreported osteoporotic vertebral fractures coming to attention as incidental findings in imaging studies [29]. This figure reflects the low reporting rates by interpreting radiologists. Bartalena $\mathrm{T}$ et al. reported that only $15 \%$ of vertebral fractures had been noted in the radiology final report, most likely because of unawareness of their clinical importance [30].

In general clinical practice, subjective visual diagnostic methods are used. However, these are considered as being not reproducible enough for epidemiological studies [31]. Also, usually the more severe fractures tend to come to attention in clinical practice. Mild fractures are also of clinical importance despite being under diagnosed [32].

Many patients with thoracolumbar vertebral fractures may be treated on an out-patient basis. Richard Hu et al. [2] showed that a large percentage of all osteoporotic fractures were treated as out-patients, In our study we did not capture the patients treated as outpatients. We had only information on the patients discharged from hospitals. Also a few patients who died prior to admission to hospital could be missed. However, in the year 2007 there were only 4 patients out of 91,820 deaths in Sweden who had vertebral fracture as underlying cause of death [24]. These injuries could also be missed in polytrauma patients. However, the vast majority of thoracolumbar vertebral fractures due to high energy trauma are diagnosed and treated as inpatients.

We can only speculate regarding which factors contribute to the decreased incidence in our study. Many accident prevention programs have been launched in several areas, i.e. road safety, leisure time accident prevention training, fall prevention devices in geriatric care and pharmacologic prophylaxis against osteoporosis.

In order to include all potential thoracolumbar spine fractures we include disc ruptures. It is of course questionable if these can be counted as thoracolumbar fractures. However, we found only 8 patients per year $(=0.03 \%)$ with that diagnose. The reason for including sacral fracture in the study was that in axial trauma an spinopelvic dissociation can arise associated with lumbar spine surgery. This injury should strictly be defined as a pelvic or lumbosacral injury. This leads to a thoracolumbar fracture overestimation of $0.6 \%$.

A major strength of our study is the calculation of population based incidence rate of fractures and surgical 
procedures based on nation wide and complete in patient registration systems.

During the duration of this study, we observed an increasing incidence of operations among patients older than 60 years. A possible explanation of this could be the introduction of new surgical methods [33].

We found that the probability of surgery was lower among women compared to men. The influence of sex and gender on musculoskeletal health has been reported by Tosi et al. [34] who discussed the biological basis for differences in injury mechanism, pain sensation, drug handling, and healing response that cannot be explained simply by hormone levels.

Patients of male sex, younger age, high-energetic trauma or with lumbar fractures had an increased probability of surgery. In patients with spinal cord injury the mean age is around 30 years and $80 \%$ of them are men [35]. This figure indicates that high-risk behaviour is more common among young men. High-energetic trauma is strongly related to more severe vertebral injury and subsequently a higher indication for surgery. Even in patients older than 60 men have high risk behaviour falling from heights or have more transport accidents. Most fracture occurs in the lumbar region (thoracolumbar), whereas the thoracic cage does not protect the spine as well [36].

The study also showed signs of regional differences in the incidence of operations. The data may reflect considerable regional differences in treatment strategies among spine surgeons. The optimal treatment of patients with spinal fracture has been debated for years, and numerous studies have been published [16, 18, 21, 22].

As opposed to common belief in the medical community the study reported low case fatality rates in our surgically treated cohort (90-day 1.4\%) [2]. An explanation could be that these patients are healthier than the general population or by advances in the perioperative management. In previous studies the case fatality rate was calculated at time at risk. This loses $1 / 12$ in the tail-end and that would not influence the results.

Unfortunately we did not include co-morbidity or coexisting injuries in our study. Therefore, the relative risk of dying could have been higher in patients who were not operated on. Others have shown that the relative risk of death was very high in young individuals and decreased in both sexes with age [37]. The reason for this is not known but may be related to severe trauma injuries or other significant co-morbidity. Our analyses of the case fatality rate was limited to patients operated on and could therefore be a source of bias because very severe co-morbidity could have been a contra-indication for surgical intervention.

Kanis et al. showed excess mortality after hospitalization for all vertebral fractures in Sweden between the years 1987 and 1996 [37]. In comparison to our cohort, they included only patients older than 50 years. They reported that the risk of death was markedly increased immediately after the event of the vertebral fracture. After a short period of declining risk, the risk increased with age at a rate which was higher than that of the general population and comparable to the rate that 1 year after a hip fracture. The latter function was assumed to be due to deaths related to co-morbidity and the residuum assumed to be due to the vertebral fracture.

Our study includes all thoracolumbar fractures regardless of the energy of trauma or if patients have fragility fractures i.e. osteoporosis. Unfortunately we could not extract if the patient has osteoporosis. The results have to be interpreted with caution due to the different risk factors in these subgroups (high energy trauma vs. osteoporosis). Geriatric high energy trauma is common and makes this analysis even more complex [38]. The type of injuries and outcomes associated with particular mechanisms of injury is therefore important to further study. Performing an evaluation during a longer time period will reflect time trends and the results of preventions of injuries will be possible to study.

In conclusion, our study gives new information on the burden of thoracolumbar vertebral fractures as well as important information about the surgical incidence and differences according to gender and age. This information should be taken into consideration in the planning of health care and when studies are planned.

Open Access This article is distributed under the terms of the Creative Commons Attribution Noncommercial License which permits any noncommercial use, distribution, and reproduction in any medium, provided the original author(s) and source are credited.

\section{References}

1. Chen HY, Chiu WT, Chen SS, Lee LS, Hung CI, Hung CL, Wang YC, Hung CC, Lin LS, Shih YH. A Nationwide epidemiological study of spinal cord injuries in Taiwan from July 1992 to June 1996. Neurol Res. 1997;19:617-22.

2. Hu R, Mustard CA, Burns C. Epidemiology of incident spinal fracture in a complete population. Spine. 1996;21:492-9.

3. Belmont PJ Jr, Taylor KF, Mason KT, Shawen SB, Polly DW Jr, Klemme WR. Incidence, epidemiology, and occupational outcomes of thoracolumbar fractures among U.S. Army aviators. J Trauma. 2001;50:855-61.

4. Bengner U, Johnell O, Redlund-Johnell I. Changes in incidence and prevalence of vertebral fracture during 30 years. Calcif Tissue Int. 1988;42:293-6.

5. Cooper C, Atkinson EJ, O'Fallon WM, Melton LJ. Incidence of clinically diagnosed vertebral fractures: a population-based study in Rochester, Minnesota, 1985-1989. J Bone Miner Res. 1992;7:221-7.

6. Kanis JA, Johnell O, Oden A, Sembo I, Redlund-Johnell I, Dawson A, De Laet C, Jonsson B. Long term risk of osteporotic fracture in Malmo. Osteoporosis Int. 2000;11:669-74. 
7. Kannus P, Niemi S, Parkkari J. Continuously increasing number and incidence of fall-induced, fracture- associated, spinal cord injuries in elderly persons. Arch Intern Med. 2000;160:2145-9.

8. Samuelsson EJ, Hanna MT, Zhang Y, Genant H, Felson DT, Kiel DP. Incidence and risk factor for vertebral fracture in women and men: 25-year follow-up results from the population-based Framingham study. J Bone Miner Res. 2006;21:1207-14.

9. Van der Klift M, De Laet CE, McCloskey EV, Hofman A, Pols HA. The incidence of verteberal fractures in men and women: the Rotterdam Study. J Bone Miner Res. 2002;17:1051-6.

10. Robertsson A, Branfoot T, Barlow F, Giannoudis P. Spinal injury pattern resulting from car and motorcycle accidents. Spine. 2002;24:2825-30.

11. Robert F, McLain MD. Functional outcomes after surgery for spinal fractures: return to work and activity. Spine. 2004;29: 470-7.

12. Denis F, Amstrong GW, Searls K, Matta L. Acute thoracolumbar burst fracture in the absence of neurologic deficit: a comparison between operative and non operative treatment. Clin Orthop. 1984;189:142-9.

13. Glenn R, Rechtine II. Non-operative management and treatment of spinal injuries. Spine. 2006;31:S22-7.

14. Hartman MB, Crin AM, Rechtine GR. Non-operative treatment of thoracolumbar fractures. Paraplegica. 1995;33:73-6.

15. Moller A, Hasserius R, Redlund-Johnell I, Ohlin A, Karlsson MK. Nonoperatively treated burst fractures of the thoracic and lumbar spine in adults: a 23- to 41-year follow-up. Spine J. 2007;7(6):701-7.

16. Mumford J, Weinstein JN, Spratt KF, Goel VK. Thoracolumbar burst fracture: the clinical efficacy and outcome of nonoperative management. Spine. 1993;18:955-70.

17. Parker JW, Lane JR, Karaikovic EE, Gaines RW. Successful short-segment instrumentation and fusion for thoracolumbar spine fractures: a consecutive 41/2-year series. Spine. 2000;25: 1157-70.

18. Shen WJ, Shen YS. Nonsurgical treatment of three-column thoracolumbar junction burst fractures without neurologic deficit. Spine. 1999;24:412-5.

19. Shen WJ, Liu TJ, Shen YS. Nonoperative treatment versus posterior fixation for thoracolumbar junction burst fractures without neurologic deficit. Spine. 2001;26:1038-45.

20. Vaccaro AR, Zeiller SC, Hulbert RJ, Anderson PA, Harris M, Hedlund R, Harrop J, Dvorak M, Wood K, Fehlings MG, Fisher C, Lehman RA Jr, Anderson DG, Bono CM, Kuklo T, Oner FC. The thoracolumbar injury severity score: a proposed treatment algorithm. J Spinal Disord Tech. 2005;18:209-15.

21. van der Roer N, de Lange ES, Bakker FC, de Vet HC, van Tulder MW. Management of traumatic thoracolumbar fractures: a systematic review of the literature. Eur Spine J. 2005;14:527-34.

22. Verlaan JJ, Diekerhof CH, Buskens E, van der Tweel I, Verbout AJ, Dhert WJ, Oner FC. Surgical treatment of traumatic fractures of the thoracic and lumbar spine. A systematic review of the literature on techniques, complications, and outcome. Spine. 2004;29:803-14.
23. Wood K, Buttermann G, Mehbod A, Garvey T, Jhanjee R, Sechriest V, Butterman G. Operative compared with nonoperative treatment of a thoracolumbar burst fracture without neurological deficit. A prospective, randomized study. J Bone Joint Surg Am. 2003;85-A:773-81 (Erratum in: J Bone Joint Surg Am. 2004;86-A:1283).

24. Statistics Sweden. The National Board of Helth and Welfare. The Swedish Hospital Discharge Register. Socialstyrelsen 2007. http://www.sos.se/epc/english/ParEng.htm.

25. Nilsson AC, Spetz CL, Carsjo K, Nightingale R, Smedby B. Relability of the hospital registry. The diagnostic data are better than their reputation. Lakartidningen. 1994;598:603-5.

26. World Health Organization. International Statistical Classification of Diseases and Related Health Problems, 10th Revision. Version for 2006. http://www3.who.int/icd/currentversion/fr-icd. htm [accessed February 2007].

27. National Board of Health and Welfare. [Swedish Classification of Operations and Major Procedures. Revised version of 2004]. http://www.socialstyrelsen.se/Publicerat/2004/8608/2004-4-1.htm [accessed February 2007].

28. National Board of Health and Welfare. The Swedish Death Register. Socialstyrelsen 2005. http://www.sos.se/epc/english/ dorseng.htm.

29. Woo EK, Mansoubi H, Alyas F. Incidental vertebral fractures on multidetector CT images of the chest: prevalence and recognition. Clin Radiol. 2008;63:160-4.

30. Bartalena T, Giannelli G, Rinaldi MF, Rimondi E, Rinaldi G, Sverzellati N, Gavelli G. Prevalence of thoracolumbar vertebral fractures on multidetector $\mathrm{CT}$ : underreporting by radiologists. Eur J Radiol. 2009;69:555-9.

31. Grados F, Marcelli C, Dargent-Molina P, Roux C, Vergnol JF, Meunier PJ, Fardellone P. Prevalence of vertebral fractures in French women older than 75 years from the EPIDOS study. Bone. 2004;34(2):362-7.

32. Roux C, Fechtenbaum J, Kolta S, Briot K, Girard M. Mild prevalent and incident vertebral fractures are risk factors for new fractures. Osteoporos Int. 2007;18(12):1617-24.

33. Garfin SR, Yuan HA, Reiley MA. New technologies in spine: Kyphoplasty and vertebroplasty for the treatment of painful osteoporotic compression fractures. Spine. 2001;26:1511-5.

34. Tosi LL, Boyan BD, Boskey AL. Does sex matter in musculoskeletal health? The influence of sex and gender on musculoskeletal health. J Bone Joint Surg Am. 2005;87:1631-47.

35. The National SCI Database. US National Spinal Cord Injury. Available at: http://www.spinalcord.uab.edu.

36. Magerl F, Aebi M, Gertzbein SD, Harms J, Nazarian S. A comprehensive classification of thoracic and lumbar injuries. Eur Spine J. 1994;3:184-201.

37. Kanis JA, Oden A, Johnell O, De Laet C, Jonsson B. Excess mortality after hospitalisation for vertebral fracture. Osteoporos Int. 2004;15:108-12.

38. Lane P, Sorondo B, Kelly JJ. Geriatric trauma patients-are they receiving trauma center care? Acad Emerg Med. 2003;10(3): $244-50$. 